Sharif University of Technology
Scientia Iranica
Transactions E: Industrial Engineering
SCIENTIA

\title{
A fuzzy chance-constrained programming model for integrated planning of the wheat supply chain considering wheat quality and sleep period: A case study
}

\author{
F. Pourmohammadi, E. Teimoury*, and M.R. Gholamian \\ Department of Industrial Engineering, Iran University of Science \& Technology, Tehran, Iran. \\ Received 13 June 2019; received in revised form 28 June 2020; accepted 18 October 2020
}

\author{
KEYWORDS \\ Agri-food supply \\ chain; \\ Wheat supply chain; \\ Blending; \\ Intra-layer flows; \\ Fuzzy chance- \\ constrained \\ programming.
}

\begin{abstract}
Wheat is a staple food in many countries and as a result, the first most cultivated crop worldwide. Since wheat is a vital product in terms of food security, its supply chain needs to be studied and planned carefully. This paper proposes a mixedinteger linear programming model for integrated planning of imported and domestically produced wheat that addresses supplier selection, order planning, transportation, storage, and distribution problems at the same time. Specifically, this model focuses on the wheat quality and wheat sleep period. Moreover, differentiation of long-term and shortterm storage facilities and consideration of intra-layer flows between storage facilities are other characteristics of this model. A fuzzy chance-constrained programming approach is employed to cope with the uncertainties associated with domestic supply, demand, and global wheat prices. The applicability and advantages of the developed model are demonstrated using real data from the wheat supply chain of Iran. Results illustrate that the current status of the wheat supply chain of Iran is far from optimality and there are many opportunities for improvement.
\end{abstract}

(C) 2022 Sharif University of Technology. All rights reserved.

\section{Introduction}

Wheat is cultivated on a larger land area than any other crop worldwide as it is a staple food in many countries. Iran is ranked 13 th in the world regarding the quantity of wheat production and 6th regarding consumption per capita [1]. According to the reports published annually by "Ministry of Agriculture-Jihad", wheat is cultivated in all provinces and has been the 1st

\footnotetext{
*. Corresponding author.

E-mail addresses: f-pourmohammadi@ind.iust.ac.ir (F. Pourmohammadi); Teimoury@iust.ac.ir (E. Teimoury); Gholamian@iust.ac.ir (M.R. Gholamian)
}

doi: $10.24200 /$ sci. 2020.53772 .3404 most cultivated crop in Iran for the last decade. Due to the diversity of climates in Iran, harvest begins in early spring and continues to mid-autumn. Harvested wheat has different qualities and is classified into three quality groups. If the quality of wheat is not appropriate for an intended purpose, it is blended with a certain amount of wheat from another quality group. "Blending" usually leads to double transportations (or repeat transportations), i.e., transportation from a source (A) to a destination (B) and, then, from the destination (B) to the same source (A).

Harvested wheat is transported and stored in long-term and short-term storage facilities for future consumption. In some provinces, domestic production and storage capacity are not proportional to consumption. Thus, transportations between provinces 
are common and inevitable. According to the data provided by "Iran Road Maintenance \& Transportation Organization" in 2016, about 55 percent of domestic productions were transported to another province for consumption. Also, 5 percent of total transportation between provinces constituted double transportations in 2016, from which 20 percent was necessary for blending, while the other 80 percent was due to inappropriate planning. Furthermore, wheat is imported for two reasons: first, to cover the gap between domestic production and consumption and, second, to provide high-quality wheat for blending. Imported wheat is stored in storage facilities alongside domestically harvested wheat.

The wheat supply chain of Iran is very vast and dynamic and has fundamental differences in comparison with the major producers and exporters of the world. For example, in Iran, agricultural lands are small and disperse, while many countries have specialized farms. Storage facilities in Iran are huge and located away from lands or ports. Moreover, rail transportation's share is meager, whereas, in the United States, the world's largest exporter of wheat in 2017, rail is the dominant mode of transportation for wheat and other grains [2]. Thus, the problems emerging in the wheat supply chain of Iran might be different too. In this paper, a mixed-integer linear mathematical model is proposed which can simultaneously optimize decisions about imported and domestically produced wheat, minimize costs, reduce total transportations, eliminate unnecessary double transportations, and balance quality throughout the supply chain. The proposed model considers the uncertainties associated with the quantity of domestic supply, demand, and prices of foreign suppliers. This model can support the decision-making process of the Government of Iran as the government is the manager and the major owner of the supply chain.

The rest of this paper is organized as follows: a review of related studies is presented in Section 2. In Section 3, the problem is defined and described. The mathematical model is developed and explained in Section 4. In Section 5, the solution approach is explained. Results and sensitivity analysis are presented in Section 6. Finally, Section 7 is dedicated to conclusions and recommendations for further research.

\section{Literature review}

The supply chain of agricultural products has received the attention of many researchers, and there is a rich body of literature in this area. Ahumada and Villalobos [3] reviewed the studies in the field of agri-food supply chains that were published from 1985 to 2007 and classified them based on crop type, planning scope, and modeling approaches. Tsolakis et al. [4] introduced the strategic, tactical, and operational decisions in agri-food supply chains and provided a taxonomy of the existing literature. Handayati et al. [5] reviewed the studies in the field of agri-food supply chain coordination and classified them according to dependencies, coordination mechanisms, and methodology. Kusumastuti et al. [6] investigated the complexities of agri-food supply chains and then, reviewed the studies published from 1991 to 2015 regarding agri-food supply chain activities, which include cultivation, harvesting, processing, distribution, storage, and transportation.

Some studies have focused on grain or wheat supply chain. Sheikhi and Nazeman [7] proposed a mixed-integer linear mathematical model to minimize total purchasing and transportation costs of wheat imports in Iran. Bilgen and Ozkarahan [8] concentrated on shipping and blending problems of wheat exports of Turkey. They assumed that a ship could be loaded in more than one port and blending could be done inside the ship. O'Donnell et al. [9] proposed a model for minimizing greenhouse gas emissions caused by wheat transportation in the northern U.S. and highlighted the role of rail transportation in keeping greenhouse gas emissions low. Thakur et al. [10] presented a multiobjective model to control the aggregation of different batches of bulk grain while minimizing total blending costs. The first objective minimized the number of storage bins used for blending and the second one minimized the total costs of blending and shipping.

Asgari et al. [11] developed a mixed-integer linear programming model to optimize the storage and transportation of domestically produced wheat in Iran. Casals and García [12] developed an optimization model to eliminate the import-export overlapping in Europe. They reduced the number of trips by $34 \%$. An and Ouyang [13] presented a bi-level Stackelberg leader-follower game model to maximize profits and minimize post-harvest loss. The leader is a food company that determines purchase prices and makes processing decisions, while followers are non-cooperative farmers that determine harvest time, shipment, storage, and market decisions. Hyland et al. [14] compared the impacts of using conventional rail service supported by country elevators with shuttle service supported by terminal elevators in the grain supply chain. They concluded that the shuttle service was faster and reduced supply chain costs.

Mahmoudinia et al. [15] investigated the impact of using hubs on the overall costs of the wheat supply chain network. They indicated the optimal number and location of hubs as well as the best transportation plan. Nourbakhsh et al. [16] presented a mathematical model for reducing quality and quantity harvest loss. The proposed model determines optimal transportation decisions and redesigns decisions regarding the location and capacity of new processing facilities 
and roadway/railway capacity expansion. Gholamian and Taghanzadeh [17] proposed a mixed-integer linear programming model for redesigning and planning of the wheat supply chain of Iran. They considered the possibility of exporting surplus wheat to foreign customers. However, the storage plan of domestically produced wheat is predetermined.

Mogale et al. [18] studied bulk wheat transportation and storage problems of India. They considered a two-stage supply chain network of the public distribution system. Teimoury et al. [19] used a robust scenario-based programming approach to redesigning and planning the wheat supply chain of Iran. They found optimal locations for opening new silos as well as the optimal amount of wheat imports at each port and storage and transportation plans. They differentiated between long-term and short-term storage facilities. Essien et al. [20] determined the major stockholders of grain supply chains in developing countries and developed a decision support system that could help the governments in developing countries design networks of grain storage facilities.

Hajikhani et al. [21] proposed a multi-objective model to investigate the supplier selection and order planning problems of the agricultural industry in a fuzzy environment. Since the proposed model is NPhard, the multi-objective particle swarm optimization algorithm is employed to obtain the results. Mogale et al. [22] presented an integrated multi-objective model for grain silo location-allocation problem that considers supply chain costs as well as total lead time. They used two Pareto-based multi-objective algorithms to solve the mixed-integer non-linear programming model. Maiyar and Thakkar [23] studied the grain transportation problem between two Indian states in the presence of hub disruption. They proposed a mixed-integer non-linear programming model and solved it using the particle swarm optimization algorithm.

In this paper, a non-deterministic mixed-integer linear programming model is presented that addresses the following problems while minimizing total costs:

1. Supplier selection and order planning based on leadtimes;

2. Transportation and storage planning of domestically produced and imported wheat;

3. Blending.

Long-term and short-term storage facilities are differentiated in the proposed model, and intra-layer flows between storage facilities are allowed to eliminate wastages and facilitate blending. To the best of our knowledge, this research is the first one that differentiates between long-term and short-term storage facilities in terms of storing restrictions and the first one considers intra-layer flows between storage facilities. Note that short-term storage facilities can hold wheat for three months, and neglecting this principle leads to both quantitative and qualitative losses. Moreover, the sleep period of domestically produced wheat is considered; in reality, wheat is not consumable immediately after harvest and must rest for about a month. Table 1 shows the contributions of this work compared to similar studies in the literature. The related papers are compared in terms of the model characteristics optimization decisions as well as consideration of uncertainty, wheat quality, sleep period, and intra-layer flows.

\section{Problem description}

The wheat supply chain consists of suppliers, storage facilities, flour factories, and consumers. In Iran, wheat is supplied by both domestic (farmers) and foreign suppliers. Farmers decide about the planting area based on the wheat guaranteed prices, which are announced annually by the government for the next crop year. After harvest, farmers determine the quantity to supply for (or sell to) the government based on various factors including guaranteed prices, global prices, and the demand of the private sector. The government is obliged to purchase all the quantity that the farmers are willing to sell. In the past five years, following the policy of achieving wheat self-sufficiency, the guaranteed prices were increased by more than $150 \%$. This incentive has increased domestic production and domestic supply from 9.3 and 4.8 in 2013 to 12.4 and 9.5 million tonnes in 2017, respectively. Total domestic supply is always less than total domestic production as farmers keep a part of their production for their consumption and next year's seed.

Wheat is imported for two reasons: first, covering the gap between domestic supply and consumption and second, providing high-quality wheat for blending as imports usually belong to the first quality group. Purchased wheat from foreign suppliers is delivered at seaports located in the north and south of Iran, as shown in Figure 1. The Caspian Sea is landlocked and has no access to open seas; hence, purchased wheat from countries like Australia can only be received at the southern ports, while wheat from countries like Russia can be received at the northern ports. Purchased wheat from both domestic and foreign suppliers is transported to storage facilities. Both rail and road transportation modes are used for transportation, although the rail's share is meager.

Storage facilities include vertical silos, automated horizontal silos, simple horizontal silos, and ground warehouses. Vertical and automated horizontal silos are long-term storage facilities that can hold wheat for three years without any quantitative or qualitative loss, 
Table 1. Comparison of this paper with previous studies.

\begin{tabular}{|c|c|c|c|c|c|c|c|c|c|c|c|c|c|c|}
\hline \multirow[b]{2}{*}{ Authors } & \multirow[b]{2}{*}{ Model } & \multirow{2}{*}{$\begin{array}{c}\text { Objective } \\
\text { function(s) }\end{array}$} & \multirow{2}{*}{$\begin{array}{c}\text { Single/ } \\
\text { multi- } \\
\text { period }\end{array}$} & \multirow{2}{*}{$\begin{array}{l}\text { Single/ } \\
\text { multi- } \\
\text { product }\end{array}$} & \multirow[b]{2}{*}{ Uncertainty } & \multicolumn{5}{|c|}{ Decisions } & \multicolumn{4}{|c|}{ Considerations } \\
\hline & & & & & & FL & IP & EP & TSP & B & $\mathbf{Q}$ & SP & DSF & ILF \\
\hline $\begin{array}{l}\text { Sheikhi and } \\
\text { Nazeman [7] }\end{array}$ & LP & Min cost & Multi & Single & & & $\checkmark$ & & $\checkmark$ & & & & & \\
\hline $\begin{array}{l}\text { Bilgen and } \\
\text { Ozkarahan [8] }\end{array}$ & MILP & Min cost & Multi & Multi & & & & $\checkmark$ & & $\checkmark$ & $\checkmark$ & & & \\
\hline $\begin{array}{l}\text { Asgari } \\
\text { et al. [11] }\end{array}$ & MILP & Min cost & Multi & Single & & & & & $\checkmark$ & $\checkmark$ & $\checkmark$ & $\checkmark$ & & \\
\hline $\begin{array}{l}\text { Mahmoudinia } \\
\text { et al. }[15]\end{array}$ & MILP & Min cost & Multi & Single & & $\mathrm{HL}$ & $\checkmark$ & & $\checkmark$ & & & & & \\
\hline $\begin{array}{l}\text { Gholamian and } \\
\text { Taghanzadeh [17] }\end{array}$ & MILP & Min cost & Multi & Multi & Scenario-based & $\checkmark$ & $\checkmark$ & $\checkmark$ & $\checkmark$ & $\checkmark$ & $\checkmark$ & & & \\
\hline $\begin{array}{l}\text { Teimoury } \\
\text { et al. [19] }\end{array}$ & MILP & Min cost & Multi & Single & Scenario-based & $\checkmark$ & $\checkmark$ & & $\checkmark$ & $\checkmark$ & $\checkmark$ & & $\checkmark$ & \\
\hline $\begin{array}{l}\text { Mogale } \\
\text { et al. [18] }\end{array}$ & MINP & Min cost & Multi & Single & & & & & $\checkmark$ & & & & & \\
\hline $\begin{array}{l}\text { Mogale } \\
\text { et al. }[22]\end{array}$ & MINP & $\begin{array}{c}\text { Min cost, } \\
\text { Min lead-time }\end{array}$ & Multi & Single & & $\checkmark$ & & & $\checkmark$ & & Det & & $\checkmark$ & \\
\hline $\begin{array}{l}\text { Maiyar and } \\
\text { Thakkar }[23]\end{array}$ & MINP & Min cost & Multi & Single & Disruption & $\mathrm{HL}$ & & & $\checkmark$ & & & & & \\
\hline This paper & MILP & Min cost & Multi & Single & FCCP & & $\checkmark$ & & $\checkmark$ & $\checkmark$ & $\checkmark$ & $\checkmark$ & $\checkmark$ & $\checkmark$ \\
\hline
\end{tabular}

Note: FL: Facility Location; IP: Imports Planning; EP: Exports Planning; TSP: Transportation and Storage Planning; B: Blending; Q: Quality; SP: Sleep Period; DSF: Differentiation between Storage Facilities; ILF: Intra-Layer Flows; LP: Linear Programming; MILP: Mixed-Integer Linear Programming; MINP: Mixed-Integer Non-Linear Programming; HL: Hub Location; FCCP: Fuzzy Chance-Constrained Programming; Det: Deterioration.

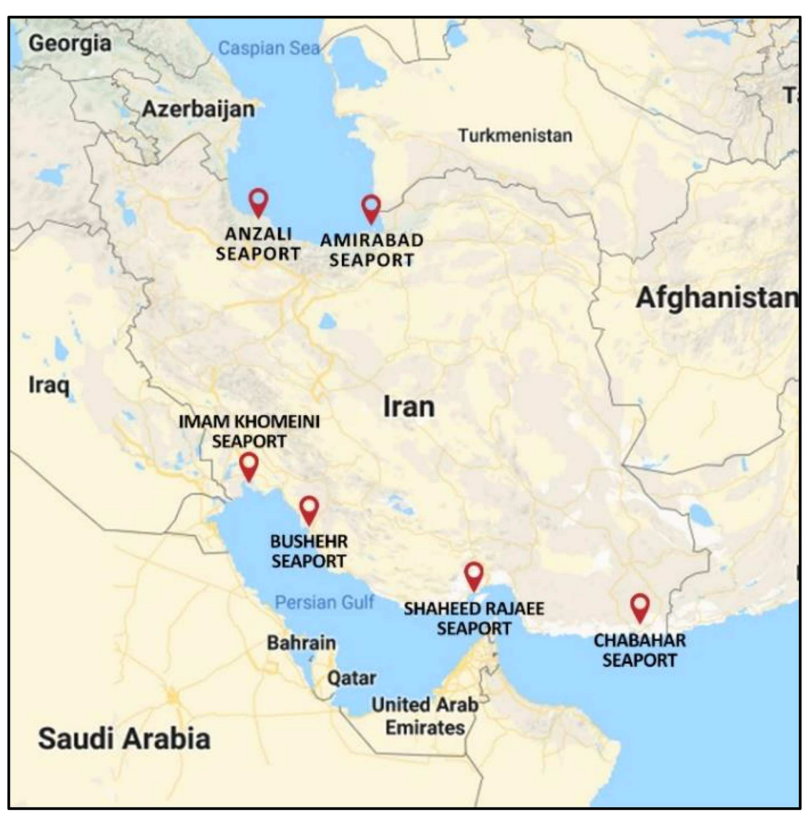

Figure 1. The location of Iran's seaports with necessary equipment for importing wheat.

while simple horizontal silos and ground warehouses are short-term storage facilities that can hold wheat for three months only. Storage facilities play two essential roles other than holding wheat: blending and letting wheat rest to become usable; because wheat is not consumable immediately after being harvested and must rest for a period, which is referred to as the sleep period. The sleep period of wheat depends on its quality and equals a month for the first and two months for the third quality group.

After the sleep period is passed, wheat is ready for consumption and is distributed among flour factories based on demand. In Iran, the available capacity of flour factories in each province is almost twice its demand. Thus, demanded flour in each province can be produced within the same province. Therefore, flour factories can be considered as actual demand zones, and vice versa. For this reason, in this paper, the wheat supply chain consists of domestic and foreign suppliers, storage facilities, and demand points, as shown in Figure 2. Assumptions are as follows:

- Production points, storage facilities, and demand points of each province are located in its center;

- The capacities of long-term and short-term storage facilities are known and fixed throughout the planning horizon;

- Short-term storage facilities can hold wheat for three months and wastage is not allowed; 


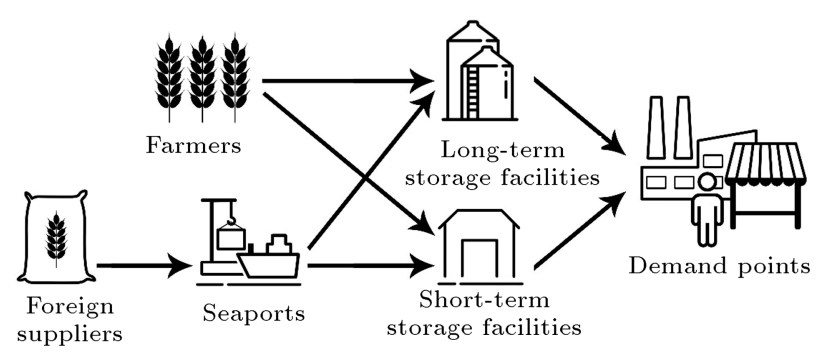

Figure 2. The structure of the wheat supply chain considered in this paper.

- Intra-layer flows from short-term storage facilities to long-term storage facilities are allowed in the model;

- Transportation and holding costs are known throughout the planning horizon;

- Rail and road transportation modes are both available for transportation;

- Purchased wheat from foreign suppliers is delivered at seaports after lead time is passed;

- The quantity of domestic supply, demand, and price of foreign suppliers are uncertain;

- For strategic reasons, the quantity of wheat which is stored in all storage facilities at the end of each period must be greater than or equal to the average demand of six months;

- Sleep period is equal to one month for all quality groups;

- Shortage is not allowed;

- Each period equals a month and the planning horizon equals 12 periods.

\section{Model formulation}

Indices, parameters, and variables used to formulate the mathematical model are as follows:

\section{Sets and indices}

$I \quad$ The set of foreign suppliers, $i \in I$

$J \quad$ The set of seaports, $j \in J$

$P \quad$ The set of production points, $p \in P$

$S \quad$ The set of storage facilities' locations, $s, s^{\prime} \in S$

$K \quad$ The set of demand points, $k \in K$

$N \quad$ The set of storage facility types: short-term and long-term, $n \in N$

$M \quad$ The set of transportation modes: rail and road, $m \in M$

$T \quad$ The set of periods, $t \in T$ $y_{i j} \quad$ Equal to 1 if the wheat purchased from supplier $i$ received at port $j, 0$ otherwise. For example, purchased wheat from Australia can only be delivered at the southern ports

price $_{i t}$ Wheat price of supplier $i$ in period $t$ (uncertain)

$L T_{i j} \quad$ Lead time: wheat purchased from supplier $i$ in period $t$ received at port $j$ in period $t+L T_{i j}$

$F C_{i} \quad$ Fixed cost of selecting supplier $i$

$c_{i j} \quad$ Maritime transportation cost from supplier $i$ to port $j$ (per tonne)

$c_{j} \quad$ Handling costs of port $j$ (per tonne)

$c_{j s m} \quad$ Transportation cost from port $j$ to storage facilities at location $s$ with transportation mode $m$ (per tonne)

$c_{p s m} \quad$ Transportation cost from production point $p$ to storage facilities at location $s$ with transportation mode $m$ (per tonne)

$c_{s k m} \quad$ Transportation cost from storage facilities at location $s$ to demand point $k$ with transportation mode $m$ (per tonne)

$c_{s s^{\prime} m} \quad$ Transportation cost from a short-term storage facility at location $s$ to a long-term storage facility at location $s^{\prime}$ with transportation mode $m$ (per tonne)

$h_{n} \quad$ Holding cost per ton per period in a storage facility of type $n$

Initials $_{s} \quad$ Initial inventory of long-term storage facilities at location $s$

$\operatorname{cap}_{i t} \quad$ The capacity of supplier $i$ in period $t$

$c a p_{s n} \quad$ The capacity of storage facility type $n$ at location $s$

cap $_{m t}$ The capacity of transportation mode $m$ in period $t$

$\widetilde{s u p}_{p t} \quad$ The quantity of wheat that is supplied by domestic farmers at production point $p$ in period $t$ (uncertain)

$q_{i} \quad$ The quality of wheat supplied by supplier $i$

$q_{p} \quad$ The quality of wheat produced at production point $p$

$Q \quad$ Acceptable quality level

$\widetilde{d e m}_{k t} \quad$ The quantity of wheat demanded at point $k$ in period $t$ (uncertain)

$D \quad$ Average annual demand (calculated based on historical data)

\section{Parameters}


$M \quad$ A big number

$\alpha, \beta \quad$ The confidence level of fuzzy constraints

\section{Decision variables}

$x_{i j t} \quad$ The quantity of wheat purchased from supplier $i$ in period $t$ that is delivered at port $j$

$x_{i j s n m t}$ The quantity of wheat that is transported from port $j$ to storage facility type $n$ at location $s$ with transportation mode $m$ in period $t$ and is originally from supplier $i$

$x_{\text {psnmt }}$ The quantity of wheat that is transported from production point $p$ to storage facility type $n$ at location $s$ with transportation mode $m$ in period $t$

$x_{\text {snkmt }}$ The quantity of wheat that is transported from storage facility type $n$ at location $s$ to demand point $k$ with transportation mode $m$ in period $t$

$x_{s s^{\prime} m t} \quad$ The quantity of wheat that is transported from a short-term storage facility at location $s$ to a long-term storage facility at location $s^{\prime}$ with transportation mode $m$ in period $t$

$I_{\text {snt }} \quad$ The total quantity of wheat that is stored in storage facility type $n$ at location $s$ at the end of period $t$

$I U U_{s n t}$ The quantity of un-usable wheat that is stored in storage facility type $n$ at location $s$ at the end of period $t$, i.e., the quantity of wheat whose sleep period has not passed

$I U_{\text {snt }} \quad$ The quantity of usable wheat stored in storage facility type $n$ at location $s$ at the end of period $t$, i.e., the quantity of wheat whose sleep period has passed

$y_{i t}$ Binary variable: Equals 1 if supplier $i$ is selected in period $t, 0$ otherwise

The objective function and constraints of the proposed mathematical model are introduced and described below:

$$
\begin{aligned}
\min z= & \sum_{i} \sum_{t} F C_{i} \cdot y_{i t} \\
& +\sum_{i} \sum_{j} \sum_{t}\left(\widetilde{\text { price }_{i t}}+c_{i j}+c_{j}\right) \cdot x_{i j t} \\
& +\sum_{i} \sum_{j} \sum_{s} \sum_{n} \sum_{m} \sum_{t} c_{j s m} \cdot x_{i j s n m t}
\end{aligned}
$$

$$
\begin{aligned}
& +\sum_{p} \sum_{s} \sum_{n} \sum_{m} \sum_{t} c_{p s m} \cdot x_{p s n m t} \\
& +\sum_{s} \sum_{k} \sum_{n} \sum_{m} \sum_{t} c_{s k m} \cdot x_{s n k m t} \\
& +\sum_{s} \sum_{s^{\prime}} \sum_{m} \sum_{t} c_{s s^{\prime} m} \cdot x_{s s^{\prime} m t} \\
& +\sum_{s} \sum_{n} \sum_{t} h_{n} \cdot I_{s n t}
\end{aligned}
$$

s.t.:

$$
\begin{aligned}
& \sum_{j} x_{i j t} \leq c a p_{i t} \cdot y_{i t} \quad \forall i, t \\
& y_{i t} \leq \sum_{j} x_{i j t} \quad \forall i, t, \\
& x_{i j t} \leq M \cdot y_{i j} \quad \forall i, j, t, \\
& x_{i j t}=\sum_{s} \sum_{n} \sum_{m} x_{i j s n m, t+L T_{i j}} \quad \forall i, j, t, \\
& \sum_{s} \sum_{n} \sum_{m} x_{p s n m t}=\widetilde{s u p}_{p t} \quad \forall p, t \\
& I U U_{s n t}=\sum_{p} \sum_{m} x_{p s n m t} \quad \forall s, n, t, \\
& I_{s n t}=\text { Initial }_{s}+\sum_{p} \sum_{m} x_{p s n m t}+\sum_{i} \sum_{j} \sum_{m} x_{i j s n m t} \\
& +\sum_{s^{\prime}} \sum_{m} x_{s^{\prime} s m t}-\sum_{k} \sum_{m} x_{s n k m t} \\
& \forall s, n=\text { longterm }, \quad t=1 \text {, } \\
& I_{s n t}=I_{s n, t-1}+\sum_{p} \sum_{m} x_{p s n m t}+\sum_{i} \sum_{j} \sum_{m} x_{i j s n m t} \\
& +\sum_{s^{\prime}} \sum_{m} x_{s^{\prime} s m t}-\sum_{k} \sum_{m} x_{s n k m t} \\
& \forall s, n=\text { longterm }, \quad t \geq 2, \\
& I_{s n t}=\sum_{t^{\prime}=t-2 \geq 1}^{t^{\prime}=t} \sum_{p} \sum_{m} x_{p s n m t^{\prime}} \\
& +\sum_{t^{\prime}=t-2 \geq 1}^{t^{\prime}=t} \sum_{i} \sum_{j} \sum_{m} x_{i j s n m t^{\prime}} \\
& -\sum_{t^{\prime}=t-2 \geq 1}^{t^{\prime}=t} \sum_{s^{\prime}} \sum_{m} x_{s s^{\prime} m t^{\prime}}
\end{aligned}
$$




$$
\begin{aligned}
& -\sum_{t^{\prime}=t-2 \geq 1}^{t^{\prime}=t} \sum_{k} \sum_{m} x_{s n k m t^{\prime}} \\
& \forall s, t, n=\text { shortterm, } \\
& I U_{s n t}=I_{s n t}-I U U_{s n t} \quad \forall s, n, t, \\
& \sum_{k} \sum_{m}\left(x_{s n k m, t+1}+x_{s n k m, t+2}\right) \\
& +\sum_{s^{\prime}} \sum_{m}\left(x_{s s^{\prime} m, t+1}+x_{s s^{\prime} m, t+2}\right) \geq I_{s n t} \\
& \forall s, t, n=\text { shortterm, } \\
& I_{\text {snt }} \leq \operatorname{cap}_{\text {sn }} \quad \forall s, n, t, \\
& \frac{\sum_{p} \sum_{m} x_{p s n m t} \cdot q_{p}+\sum_{i} \sum_{j} \sum_{m} x_{i j s n m t} \cdot q_{i}}{\sum_{p} \sum_{m} x_{p s n m t}+\sum_{i} \sum_{j} \sum_{m} x_{i j s n m t}} \leq Q \\
& \forall s, n, t, \\
& \sum_{s} \sum_{n} I_{s n t} \geq 0.5 \cdot D \quad \forall t, \\
& \sum_{s} \sum_{n} \sum_{m} x_{s n k m t}=\widetilde{\operatorname{dem}}_{k t} \quad \forall k, t, \\
& \sum_{i} \sum_{j} \sum_{s} \sum_{n} x_{i j s n m t}+\sum_{p} \sum_{s} \sum_{n} x_{p s n m t} \\
& +\sum_{s} \sum_{n} \sum_{k} x_{s n k m t}+\sum_{s} \sum_{s^{\prime}} x_{s s^{\prime} m t} \leq c a p_{m t} \\
& \forall \mathrm{m}, \mathrm{t}, \\
& x_{i j t}, x_{i j s n m t}, x_{p s n m t}, x_{s n k m t}, x_{s s^{\prime} m t}, I_{s n t}, \\
& I U_{s n t}, I U U_{s n t} \geq 0, \quad y_{i t} \in\{0,1\} .
\end{aligned}
$$

The objective function (1) minimizes total purchasing, transportation, and holding costs. Eqs. (2) and (3) guarantee that the quantity of purchased wheat from a selected supplier does not exceed its capacity. Eq. (4) indicates possible seaports that purchased wheat can be delivered. Eq. (5) determines the period in which the purchased wheat is received and makes sure that it is transported to storage facilities immediately. Eq. (6) makes sure that domestically supplied wheat is transported to storage facilities after harvest. Eq. (7) determines the amount of un-usable wheat in storage facilities, i.e., the amount of wheat that needs to rest. Eqs. (8) and (9) show the amount of wheat in longterm storage facilities. Note that long-term storage facilities are not empty at the beginning of the planning horizon, and there is some inventory available from the previous year. Eq. (10) indicates the amount of wheat in short-term storage facilities. Note that shortterm storage facilities can hold wheat for three months. Eq. (11) calculates the quantity of usable wheat in storage facilities. Eq. (12) prevents wheat wastage in short-term storage facilities. Eq. (13) guarantees that the quantity of wheat existing in a storage facility does not exceed its capacity. Eq. (14) calculates the quality of the input flow for storage facilities and makes sure it is better than the acceptable quality level. Note that the first quality group is better than the second and third ones. Eq. (15) indicates the necessity of holding strategic inventories. According to the law and for strategic reasons, the quantity of total wheat stored in all storage facilities at the end of each period must be greater than or equal to the average demand of six months. Eq. (16) guarantees that all demand is served. Eq. (17) determines the capacity of transportation modes in each period. Finally, Eq. (18) shows decision variables and their types.

The proposed model is a mixed-integer linear programming model because Eq. (14) can be rewritten as follows:

$$
\begin{aligned}
& \sum_{p} \sum_{m} x_{p s n m t} \cdot q_{p}+\sum_{i} \sum_{j} \sum_{m} x_{i j s n m t} \cdot q_{i} \\
& \quad \leq Q \cdot\left(\sum_{p} \sum_{m} x_{p s n m t}+\sum_{i} \sum_{j} \sum_{m} x_{i j s n m t}\right) \\
& \quad \forall s, n, t .
\end{aligned}
$$

The objective function (1) and Eqs. (6) and (16) include uncertain parameters. Hence, the fuzzy sets theory and, more precisely, the possibilistic programming approach are employed to cope with the uncertainties that are associated with the supplier's prices, the quantity of domestically supplied wheat, and demands. The reasons for choosing the Fuzzy Sets Theory and more details about the used approach are presented in the following section.

\section{Solution approach}

The uncertainty of data can be due to (1) randomness that comes from the random nature of parameters or (2) epistemic uncertainty that comes from lack of knowledge of the parameter values [24]. Stochastic programming approaches are employed to model the former, and possibilistic programming approaches are used to handle the latter. The lack of sufficient historical data for uncertain parameters, resulting in the absence of knowledge in estimating the actual values 
of parameters, is an essential reason for employing possibilistic programming approaches [25].

Since we face lack of sufficient and reliable historical data in the wheat supply chain, a possibilistic programming approach is used to handle the uncertain parameters. Different methods exist in the field of possibilistic programming. Here, the fuzzy chance-constrained programming approach is employed [26]. Fuzzy chance-constrained programming is a credible possibilistic programming approach that relies on strong mathematical concepts such as the expected value of a fuzzy number and the possibility and necessity measures. This approach enables the decision-maker to control the confidence level of constraints' satisfactions besides supporting various types of fuzzy numbers such as triangular and trapezoidal forms [27].

Trapezoidal possibility distributions can be de- $^{-}$ fined by their four prominent points, e.g., $\widetilde{\xi}=$ $\left(\xi^{(1)}, \xi^{(2)}, \xi^{(3)}, \xi^{(4)}\right)$, as shown in Figure 3. When $\xi^{(2)}=$ $\xi^{(3)}$, the respective trapezoidal possibility distribution is reduced into a triangular one. These two types of possibility distributions are widely applied in many types of decision-making and planning problems [28].

In this paper, all uncertain parameters, i.e., the foreign suppliers' prices, the quantity of domestically supplied wheat, and demands are assumed to be trapezoidal possibility distributions. The expected value operator is used to calculate the crisp equivalent of the objective function, and the possibility measure is employed to cope with chance constraints, meaning the constraints that include uncertain parameters. Thus, the proposed model can be rewritten as follows:

$$
\min E[z]
$$

s.t.:

$$
\begin{aligned}
& \operatorname{Pos}\left\{\sum_{s} \sum_{n} \sum_{m} x_{\text {psnmt }}=\widetilde{\sup }_{p t}\right\} \geq \alpha \quad \forall p, t, \\
& \operatorname{Pos}\left\{\sum_{s} \sum_{n} \sum_{m} x_{\text {snkmt }}=\widetilde{\operatorname{dem}}_{k t}\right\} \geq \beta \quad \forall k, t .
\end{aligned}
$$

Eqs. (2) to (5), (7) to (15), (17), and (18). The crisp equivalent of the proposed mixed-integer linear

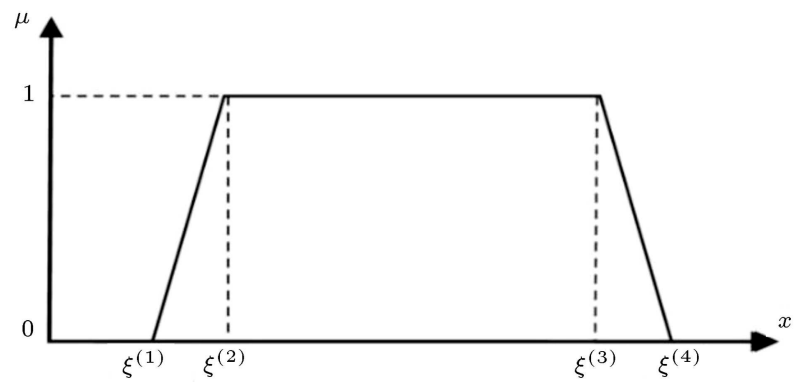

Figure 3. A trapezoidal possibility distribution. programming model can be formulated as follows (see the Appendix):

$$
\begin{aligned}
& \min \quad E[z]=\sum_{i} \sum_{t} F C_{i} \cdot y_{i t}+\sum_{i} \sum_{j} \sum_{t} \\
& \left(\frac{\text { price }_{i t}^{(1)}+\text { price }_{i t}^{(2)}+\text { price }_{i t}^{(3)}+\text { price }_{i t}^{(4)}}{4}\right. \\
& \left.+c_{i j}+c_{j}\right) \cdot x_{i j t} \\
& +\sum_{i} \sum_{j} \sum_{s} \sum_{n} \sum_{m} \sum_{t} c_{j s m} \cdot x_{i j s n m t} \\
& +\sum_{p} \sum_{s} \sum_{n} \sum_{m} \sum_{t} c_{p s m} \cdot x_{p s n m t} \\
& +\sum_{s} \sum_{k} \sum_{n} \sum_{m} \sum_{t} c_{s k m} \cdot x_{s n k m t} \\
& +\sum_{s} \sum_{s^{\prime}} \sum_{m} \sum_{t} c_{s s^{\prime} m} \cdot x_{s s^{\prime} m t} \\
& +\sum_{s} \sum_{n} \sum_{t} h_{n} \cdot I_{s n t},
\end{aligned}
$$

s.t.:

$$
\begin{aligned}
& \sum_{s} \sum_{n} \sum_{m} x_{p s n m t} \geq(1-\alpha) \cdot s u p_{p t}^{(1)}+\alpha \cdot s u p_{p t}^{(2)} \\
& \quad \forall p, t
\end{aligned}
$$

$\sum_{s} \sum_{n} \sum_{m} x_{p s n m t} \leq(1-\alpha) \cdot s u p_{p t}^{(4)}+\alpha \cdot s u p_{p t}^{(3)}$

$$
\forall p, t
$$

$$
\sum_{s} \sum_{n} \sum_{m} x_{s n k m t} \geq(1-\beta) \cdot \operatorname{dem}_{k t}^{(1)}+\beta \cdot \operatorname{dem}_{k t}^{(2)}
$$

$\forall k, t$

$$
\begin{aligned}
& \sum_{s} \sum_{n} \sum_{m} x_{s n k m t} \leq(1-\beta) \cdot d e m_{k t}^{(4)}+\beta \cdot d e m_{k t}^{(3)} \\
& \quad \forall k, t .
\end{aligned}
$$

And Eqs. (2) to (5), (7) to (15), (17), and (18).

$\alpha$ and $\beta$ are the confidence levels of chance constraints.

\section{Model implementation and results}

The proposed mathematical model is implemented 
using real data of the wheat supply chain in Iran. The data was gathered from different organizations such as "Ministry of Agriculture-Jihad", "Government Trading Organization of Iran", "Iran Road Maintenance \& Transportation Organization", "The Railways of Islamic Republic of Iran", and "Ports \& Maritime Organization of Iran". As the wheat supply chain of Iran is described in Section 3, we skip the redescription.

\subsection{Data and information}

Information regarding the size of the problem is presented in Table 2. Iran has 31 provinces and wheat is cultivated in all of them. According to the data provided by "Ministry of Agriculture-Jihad", Khuzestan, Golestan, Fars, Kordestan, and Kermanshah are among the major producers of wheat and their combined production makes up more than $20 \%$ of the annual production. Information regarding domestic production, domestic supply, imports, and demand is presented in Table 3. Major foreign suppliers of wheat from 2011 to 2016 include Argentina, Australia, Canada, the European Union, Kazakhstan, and Russia based on the data provided by "Ports \& Maritime Organization of Iran." Note that due to the growth of domestic supply, wheat imports have been prohibited since April 2016. Moreover, as is shown in Table 4, Iran has about 700 storage facilities with an overall capacity of 17.691 million tonnes for storing wheat. Unfortunately, due to data confidentiality, we are not allowed to reveal the details.

The model is coded in GAMS 24.1.2 and is solved by CPLEX solver. The duality gap has been set to zero to obtain optimal solutions. All tests are carried out on an Intel Core i7-5500U $2.40 \mathrm{GHz}$ computer with 8.00 GB RAM. It should be noted that due to cur-
Table 4. Capacity of storage facilities.

\begin{tabular}{lc}
\hline $\begin{array}{c}\text { Type of } \\
\text { storage facility }\end{array}$ & $\begin{array}{c}\text { Capacity } \\
\text { (thousand tonnes) }\end{array}$ \\
\hline Long-term & 12622 \\
Short-term & 5069 \\
Sum & 17691 \\
\hline
\end{tabular}

rency fluctuations, all of the monetary-related data are presented in Iranian Rial. Wheat prices are obtained from indexmundi.com for the corresponding years, and the exchange rate for global prices is considered 42000 (1 United States Dollar equals 42000 Iranian Rials) because as wheat is a staple food, the government grants subsidies for its supply to keep the bread prices low. Thus, the exchange rate is decided and fixed throughout every fiscal year and does not fluctuate.

\subsection{Results and sensitivity analysis}

First, in order to evaluate the current status of the wheat supply chain of Iran, the proposed model is solved using the corresponding data from the years 2013 to 2016. Table 5 shows the improvements when importing, storage, and transportation plans are optimized. Initial inventory of the year 2013 is considered 3 million tonnes (based on historical data) and the initial inventory of subsequent years is calculated based on data regarding domestic supply and imports. As data is known, we face no uncertainty. Also, since the data regarding transportations from storage facilities to demand zones were not available, we only compared transportations to storage facilities.

As is shown in Table 5, optimization of decisions will lead to significant improvements in transportation and costs; however, the quantity of imported wheat

Table 2. The values assigned to indexes.

\begin{tabular}{cll}
\hline Index & \multicolumn{1}{c}{ Description } & \multicolumn{1}{c}{ Details } \\
\hline$i$ & Foreign suppliers & Argentina, Australia, Canada, European Union, Kazakhstan, Russia \\
$j$ & Seaports & Imam Khomeini, Shaheed Rajaee, Chabahar, Bushehr, Anzali, Amirabad \\
$p, s, k$ & Provinces & 31 \\
$n$ & Type of storage facilities & Short-term and long-term \\
$m$ & Transportation modes & Rail and road \\
$t$ & Periods & 12 months (one year) \\
\hline
\end{tabular}

Table 3. Historical data regarding wheat production, supply, and demand (tonnes).

\begin{tabular}{ccccc}
\hline Year & Domestic production & Domestic supply & Imports & Total demand \\
\hline 2013 & 9304246 & 4820500 & 3404000 & 9051900 \\
2014 & 10578698 & 6716600 & 5275800 & 8930200 \\
2015 & 11522318 & 8082000 & 334000 & 7465700 \\
2016 & 14592003 & 11519700 & 544200 & 8955000 \\
2017 & 12400000 & 9500000 & 0 & 8900000 \\
\hline
\end{tabular}


Table 5. Results of the proposed model vs. real data regarding imports and transportations (years 2013-2016).

\begin{tabular}{|c|c|c|c|c|c|}
\hline Data and & esults (metric tonnes) & 2013 & 2014 & 2015 & 2016 \\
\hline \multirow{3}{*}{ Parameters } & Domestic supply & 4820500 & 6716600 & 8082000 & 11519700 \\
\hline & Demand & 9051900 & 8930200 & 7465700 & 8955000 \\
\hline & Initial inventory & 3000000 & 2172600 & 5234800 & 6185100 \\
\hline \multirow{2}{*}{ Real data } & Imported wheat & 3404000 & 5275800 & 334000 & 544200 \\
\hline & Transportations & 12637357 & 18577235 & 13276504 & 18923700 \\
\hline \multirow{2}{*}{ Optimal results } & Optimal imported wheat & 5225460 & 4074524 & 307938 & 866857 \\
\hline & Optimal transportations & 11700790 & 11680230 & 8389938 & 14462100 \\
\hline \multirow{2}{*}{ Improvements } & Changes in imported volume & $53.5 \%$ & $-22.8 \%$ & $-7.8 \%$ & $59.3 \%$ \\
\hline & Changes in transportations & $-7.4 \%$ & $-37.1 \%$ & $-36.8 \%$ & $-23.6 \%$ \\
\hline
\end{tabular}

is not always enhanced. The first exception was the quantity of imported wheat in 2013. Note that in 2013, the necessity of holding strategic inventories was neglected by the government, but the proposed model is obliged to hold them; therefore, optimal imported wheat is more than historical data. The second exception was the quantity of imported wheat in 2016. The proposed model suggested that we should have imported 866857 tonnes, while in 2016, 544200.3 tonnes were imported, because wheat import was prohibited from April 2016. In 2016, domestically produced wheat could cover the demand; hence, the optimal imports which are suggested by the proposed model are required for blending. However, the actual imports indicate that the acceptable quality level might have been slightly ignored.

Then, the year 2016 was investigated more thoroughly. In 2016, on average, $45 \%$ of a province's domestic supply was consumed inside the province and $55 \%$ was transported to other provinces. However, in the proposed model, $69 \%$ is consumed inside the province and $31 \%$ is transported to other provinces. This change has a considerable effect on total road traffic and shows the necessity of revisiting storage plans. Also, the farmers who produce high-quality wheat usually do not agree on the withdrawal of highquality wheat from their provinces and the entry of lowquality wheat from other provinces, which is conducted for blending. Therefore, reducing transportations to other provinces ensures farmers' satisfaction.

Second, optimal rail transportations were investigated. As was mentioned before, in Iran, unlike the world's primary producers and exporters of wheat, the share of rail transportation is meager. In fact, it has never exceeded 500000 tonnes a year. Therefore, we investigated optimal rail transportations from the year 2013 to 2016. The results are presented in Table 6 . Note that the rail capacity for transporting bulk grain is considered 100000 tonnes per month.

As the rail capacity for transporting bulk grain seems to be a limiting factor in the transportation of imported wheat, we also investigated optimal rail transportation when the rail capacity is increased by 25, 50, and $100 \%$. The results are presented in Figures 4 and 5. According to Figure 4 and Table 5, as imports increase, rail transportation increases too

Table 6. Results of the proposed model vs. real data regarding rail transportations (years 2013-2016).

\begin{tabular}{|c|c|c|c|c|c|}
\hline \multicolumn{2}{|c|}{ Data and results (metric tonnes) } & 2013 & 2014 & 2015 & 2016 \\
\hline \multirow{3}{*}{ Parameters } & Domestic supply & 4820500 & 6716600 & 8082000 & 11519700 \\
\hline & Demand & 9051900 & 8930200 & 7465700 & 8955000 \\
\hline & Initial inventory & 3000000 & 2172600 & 5234800 & 6185100 \\
\hline Real data & Rail transportations & 7000 & 410000 & 479000 & 230000 \\
\hline \multirow{3}{*}{ Optimal rail transportations } & Total & 966167.8 & 753783.5 & 601577.4 & 665674.5 \\
\hline & From seaports to storage facilities (imports) & 500000.0 & 400000.0 & 114312.5 & 298770.9 \\
\hline & Others & 466167.8 & 353783.5 & 487264.9 & 366903.6 \\
\hline Increase (improvement) & & 959167.8 & 343783.5 & 122577.4 & 435674.5 \\
\hline
\end{tabular}




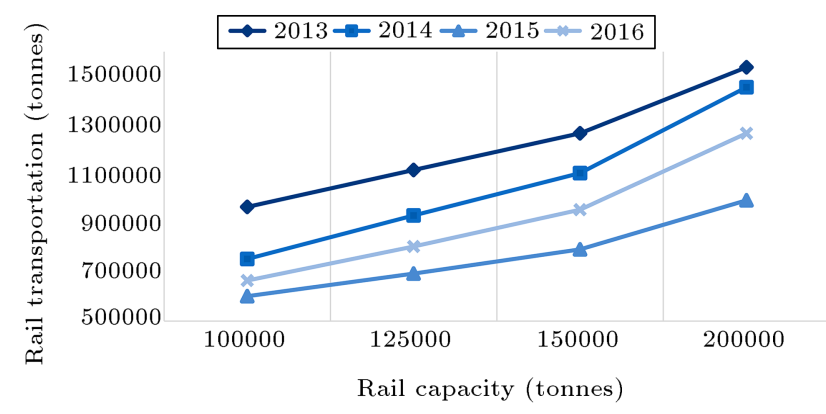

Figure 4. Total rail transportations for different capacities.

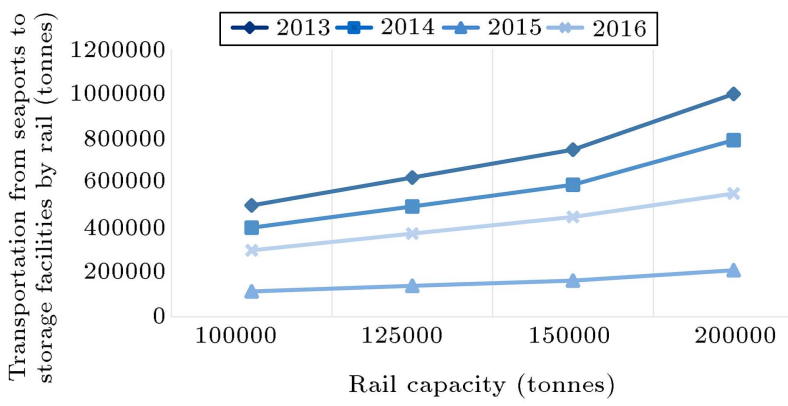

Figure 5. Rail transportation from seaports to storage facilities for different capacities.

(2013 has the highest imported quantity and rail transportation). On average, about $44 \%$ of total rail transportation is dedicated to transporting wheat from seaports to storage facilities (imports). Also, as is shown in Figure 5, rail capacity is indeed a limiting factor in rail transportation. It should be noted that the rail capacity for transporting solid bulk goods is far more than 100000 tonnes per month. However, the transportation cost is calculated based on the distance traveled and the quantity (tonne-kilometer), and as the density of grain is lower than other bulk goods such as coal, little capacity is dedicated to the transportation of grains.

Third, the effects of considering lateral transshipments or intra-layer flows (from short-term storage facilities to long-term storage facilities) on total costs are evaluated. To this end, the results of the proposed model with and without permission for intra-layer flows $\left(x_{s s^{\prime} m t}\right)$ are compared to each other for some possible hypothetical and real situations. We created nine test problems in which domestic supply is about 8,10 , and 12 million tonnes and demand is about 8, 9, and 10 million tonnes. Domestic supply and demand (fuzzy numbers) are perceived as symmetric trapezoidal possibility distributions, as shown in Table 7 . Each test problem is solved with different values of $\alpha$ and $\beta$. Overall, the problem is solved 90 times for Table 7 . Note that the initial inventory is considered 4 million tonnes for all test problems.

As is shown in Table 7, considering intra-layer

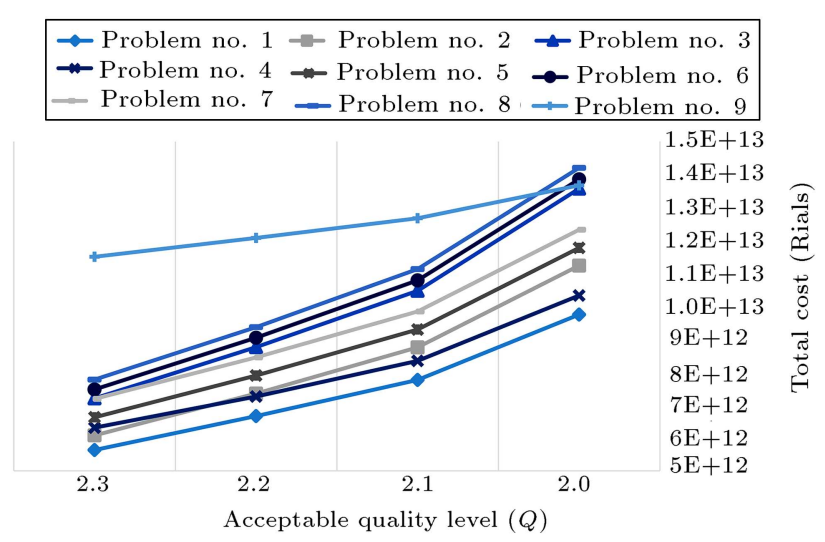

Figure 6. Total costs against the acceptable quality level.

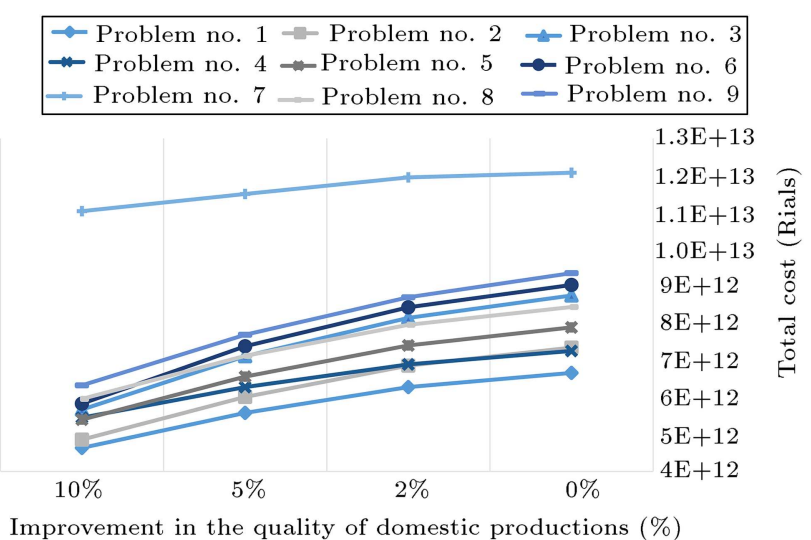

Figure 7. Total costs against the quality of domestic productions.

flows between storage facilities reduces total costs when domestic supply is about 12 million tonnes. As the difference between domestic supply and demand increases, the cost reduction becomes more significant. Note that all costs in Table 7 are in million Rials and the results are rounded to one decimal place. Thus, in some problems, the improvement caused by intra-layer flows is "almost" zero. Also, Problem no. 7 has the highest costs due to wheat import to cover demand.

The fact that intra-layer flows can reduce costs is fundamental. As short-term storage facilities can hold wheat for three months without quantitative and qualitative loss, available wheat in these facilities must be sent for consumption or be transported to longterm storage facilities before it deteriorates. Hence, short-term storage facilities are considered costly and unfavorable. As a result, they are only used when longterm storage facilities are fully occupied. However, as shown in Table 7 , appropriate usage of short-term storage facilities does not increase costs and, in some cases, it can lead to cost reduction.

Finally, the sensitivity of the objective function to the acceptable quality level and quality of domestic productions are analyzed for the problems defined in Table 7 . Figures 6 and 7 represent the results graph- 
Table 7. Effects of considering intra-layer flows on total costs.

\begin{tabular}{|c|c|c|c|c|c|c|c|}
\hline \multirow[b]{2}{*}{$\begin{array}{l}\text { Problem } \\
\text { no. }\end{array}$} & \multicolumn{2}{|c|}{$\begin{array}{c}\text { Parameters } \\
\text { (million tonnes) }\end{array}$} & \multicolumn{2}{|c|}{$\begin{array}{c}\text { Confidence } \\
\text { levels }\end{array}$} & \multicolumn{2}{|c|}{$\begin{array}{c}\text { Total costs } \\
\text { (million rials) }\end{array}$} & \multirow[b]{2}{*}{ Improvement } \\
\hline & $\begin{array}{l}\text { Domestic } \\
\text { supply }\end{array}$ & Demand & $\alpha$ & $\beta$ & $\begin{array}{c}\text { With } \\
\text { intra-layer } \\
\text { flows }\end{array}$ & $\begin{array}{c}\text { Without } \\
\text { intra-layer } \\
\text { flows }\end{array}$ & \\
\hline \multirow{5}{*}{1} & \multirow{5}{*}{$(7.5,7.9,8.1,8.5)$} & \multirow{5}{*}{$(7.5,7.9,8.1,8.5)$} & 1 & 1 & 6722649.9 & 6722649.9 & 0 \\
\hline & & & 0.9 & 0.9 & 6662660.2 & 6662660.2 & 0 \\
\hline & & & 0.9 & 0.8 & 6637852.9 & 6637852.9 & 0 \\
\hline & & & 0.8 & 0.9 & 6627477.9 & 6627477.9 & 0 \\
\hline & & & 0.8 & 0.8 & 6602670.4 & 6602670.4 & 0 \\
\hline \multirow{5}{*}{2} & \multirow{5}{*}{$(9.5,9.9,10.1,10.5)$} & \multirow{5}{*}{$(7.5,7.9,8.1,8.5)$} & 1 & 1 & 7408296.4 & 7408296.4 & 0 \\
\hline & & & 0.9 & 0.9 & 7346019.5 & 7346019.5 & 0 \\
\hline & & & 0.9 & 0.8 & 7321249.7 & 7321249.7 & 0 \\
\hline & & & 0.8 & 0.9 & 7308518.9 & 7308518.9 & 0 \\
\hline & & & 0.8 & 0.8 & 7283749.3 & 7283749.3 & 0 \\
\hline \multirow{5}{*}{3} & \multirow{5}{*}{$(11.5,11.9,12.1,12.5)$} & \multirow{5}{*}{$(7.5,7.9,8.1,8.5)$} & 1 & 1 & 8854063.9 & 8886186.0 & 32122.1 \\
\hline & & & 0.9 & 0.9 & 8755211.8 & 8784327.1 & 29115.3 \\
\hline & & & 0.9 & 0.8 & 8721772.0 & 8750024.0 & 28252.0 \\
\hline & & & 0.8 & 0.9 & 8690078.1 & 8716936.0 & 26857.9 \\
\hline & & & 0.8 & 0.8 & 8656658.2 & 8682633.5 & 25975.3 \\
\hline \multirow{5}{*}{4} & \multirow{5}{*}{$(7.5,7.9,8.1,8.5)$} & \multirow{5}{*}{$(8.5,8.9,9.1,9.5)$} & 1 & 1 & 7322320.6 & 7322335.2 & 14.6 \\
\hline & & & 0.9 & 0.9 & 7256554.8 & 7256554.8 & 0 \\
\hline & & & 0.9 & 0.8 & 7227452.8 & 7227452.8 & 0 \\
\hline & & & 0.8 & 0.9 & 7224411.9 & 7224411.9 & 0 \\
\hline & & & 0.8 & 0.8 & 7194409.9 & 7194409.9 & 0 \\
\hline \multirow{5}{*}{5} & \multirow{5}{*}{$(9.5,9.9,10.1,10.5)$} & \multirow{5}{*}{$(8.5,8.9,9.1,9.5)$} & 1 & 1 & 7955115.9 & 7955115.9 & 0 \\
\hline & & & 0.9 & 0.9 & 7892724.2 & 7892724.2 & 0 \\
\hline & & & 0.9 & 0.8 & 7867830.7 & 7867830.7 & 0 \\
\hline & & & 0.8 & 0.9 & 7855228.5 & 7855228.5 & 0 \\
\hline & & & 0.8 & 0.8 & 7830334.5 & 7830334.5 & 0 \\
\hline \multirow{5}{*}{6} & \multirow{5}{*}{$(11.5,11.9,12.1,12.5)$} & \multirow{5}{*}{$(8.5,8.9,9.1,9.5)$} & 1 & 1 & 9138048.5 & 9146790.8 & 8742.3 \\
\hline & & & 0.9 & 0.9 & 9041577.4 & 9049210.7 & 7633.3 \\
\hline & & & 0.9 & 0.8 & 9008485.3 & 9016074.4 & 7589.1 \\
\hline & & & 0.8 & 0.9 & 8975737.3 & 8984819.1 & 9081.8 \\
\hline & & & 0.8 & 0.8 & 8938076.9 & 8947149.4 & 9072.5 \\
\hline \multirow{5}{*}{7} & \multirow{5}{*}{$(7.5,7.9,8.1,8.5)$} & \multirow{5}{*}{$(9.5,9.9,10.1,10.5)$} & 1 & 1 & 12516305.0 & 12516305.0 & 0 \\
\hline & & & 0.9 & 0.9 & 12072252.3 & 12072252.3 & 0 \\
\hline & & & 0.9 & 0.8 & 11844391.4 & 11844391.4 & 0 \\
\hline & & & 0.8 & 0.9 & 11844391.2 & 11844391.2 & 0 \\
\hline & & & 0.8 & 0.8 & 11628203.3 & 11628203.3 & 0 \\
\hline
\end{tabular}


Table 7. Effects of considering intra-layer flows on total costs (continued).

\begin{tabular}{|c|c|c|c|c|c|c|c|}
\hline \multirow[b]{2}{*}{$\begin{array}{l}\text { Problem } \\
\text { no. }\end{array}$} & \multicolumn{2}{|c|}{$\begin{array}{c}\text { Parameters } \\
\text { (million tonnes) }\end{array}$} & \multicolumn{2}{|c|}{$\begin{array}{c}\text { Confidence } \\
\text { levels }\end{array}$} & \multicolumn{2}{|c|}{$\begin{array}{c}\text { Total costs } \\
(\text { million rials })\end{array}$} & \multirow[b]{2}{*}{ Improvement } \\
\hline & $\begin{array}{l}\text { Domestic } \\
\text { supply }\end{array}$ & Demand & $\alpha$ & $\boldsymbol{\beta}$ & $\begin{array}{c}\text { With } \\
\text { intra-layer } \\
\text { flows }\end{array}$ & $\begin{array}{c}\text { Without } \\
\text { intra-layer } \\
\text { flows }\end{array}$ & \\
\hline \multirow{5}{*}{8} & \multirow{5}{*}{$(9.5,9.9,10.1,10.5)$} & \multirow{5}{*}{$(9.5,9.9,10.1,10.5)$} & 1 & 1 & 8507260.4 & 8507260.4 & 0 \\
\hline & & & 0.9 & 0.9 & 8445181.1 & 8445181.1 & 0 \\
\hline & & & 0.9 & 0.8 & 8420244.0 & 8420244.0 & 0 \\
\hline & & & 0.8 & 0.9 & 8408108.8 & 8408108.8 & 0 \\
\hline & & & 0.8 & 0.8 & 8383176.2 & 8383176.2 & 0 \\
\hline \multirow{5}{*}{9} & \multirow{5}{*}{$(11.5,11.9,12.1,12.5)$} & \multirow{5}{*}{$(9.5,9.9,10.1,10.5)$} & 1 & 1 & 9464403.6 & 9468067.3 & 3663.7 \\
\hline & & & 0.9 & 0.9 & 9360708.9 & 9361933.5 & 1224.6 \\
\hline & & & 0.9 & 0.8 & 9326127.9 & 9327349.0 & 1221.1 \\
\hline & & & 0.8 & 0.9 & 9292458.7 & 9293652.5 & 1193.8 \\
\hline & & & 0.8 & 0.8 & 9258081.4 & 9259144.5 & 1063.1 \\
\hline
\end{tabular}

ically. Note that the initial inventory is considered 4 million tonnes and $\alpha=\beta=0.9$. Also, assuming that the first quality group cannot be enhanced further, the improvement in the quality of domestic productions is only considered in the second and third quality groups.

As is shown in Figure 6, increasing the acceptable quality level to 2.3 decreases total costs by $14 \%$ on average because it reduces the need for blending and hence, importing and transportations. Also, decreasing the acceptable quality level to 2 and 2.1 increases total costs by about $45 \%$ and $16 \%$, respectively. This result clearly shows the role of blending in increasing transportations and costs. The quality of domestic productions $\left(q_{p}\right)$ has a great impact on total costs too, as shown in Figure 7. Ten percent improvement in the quality of domestically supplied wheat reduces total costs by $29 \%$ (on average). Also, a $5 \%$ improvement can reduce costs by $15 \%$ (on average). Note that at present, guaranteed prices are independent of quality and farmers have no incentive for enhancing qualities. Therefore the government needs to revisit the pricing policies, as the quality of domestically-supplied wheat has a significant role in total costs. Also, in Problem no 7 , about 1.7 million tonnes of high-quality wheat is imported; hence, the impact of acceptable quality level and quality improvements are less remarkable.

\subsection{Investigation of the feasible region}

The proposed mathematical model faces limited resources, which can affect the feasible region. These resources include the capacity of foreign suppliers, the capacity of transportation modes, and the capacity of storage facilities. In this paper, six foreign suppliers are considered (Table 2). In 2019, Argentina, Australia, Canada, European Union, Kazakhstan, and Russia exported $13,8.2,23.5,32,6$, and 34 million tonnes, respectively. Thus, the total capacity equals 116.7 million tonnes. Considering the total demand for wheat in Iran (Table 3), the corresponding constraint is non-binding. Also, the capacity of transportation modes in each period (month) equals 15 and 0.1 million tonnes for road and rail, respectively. Therefore, the corresponding constraint is non-binding too. Problem no. 1 in Table 8 shows that when domestic supply is at its lowest (about 5 million tonnes), demand is at its highest (about 10 million tonnes). Covering demand relies on imports, the capacity of foreign suppliers is enough, and the problem remains feasible. Also, Problem no. 2 indicates that transportation capacity is enough and the problem remains feasible when both domestic supply and demand are at their highest.

However, the capacity of storage facilities can be a scarce resource. Due to the necessity of holding strategic inventories, storage facilities are not empty at the beginning of the year. Also, the government is obliged to purchase all the quantity that the farmers (domestic suppliers) are willing to sell. Moreover, the second and third quality groups are not appropriate for exports, and the first quality group is required for blending; hence, the withdrawal from storage facilities equals domestic demand.

Since short-term storage facilities cannot hold wheat for more than three months, the capacity of long-term storage facilities is a scarce resource and a 
Table 8. Investigation of the feasible region.

\begin{tabular}{ccccccc}
\hline \multirow{2}{*}{$\begin{array}{c}\text { Problem } \\
\text { no. }\end{array}$} & \multicolumn{3}{c}{ Parameters (million tonnes) } & & \multicolumn{2}{c}{ Optimal results } \\
\cline { 2 - 4 } \cline { 6 - 7 } 1 & Initial inventory & Domestic supply & Demand & & Imports & Total costs (million rials) \\
\hline 2 & 4 & $(4.5,4.9,5.1,5.5)$ & $(9.5,9.9,10.1,10.5)$ & & 5.7 & 36167378.5 \\
3 & 4 & $(11.5,11.9,12.1,12.5)$ & $(9.5,9.9,10.1,10.5)$ & & 2.2 & 17455763.9 \\
4 & 4 & $(7.5,7.9,8.1,8.5)$ & $(7.5,7.9,8.1,8.5)$ & & 0.80 & 6662660.2 \\
5 & 6 & $(7.5,7.9,8.1,8.5)$ & $(7.5,7.9,8.1,8.5)$ & & 0.29 & 3027701.5 \\
6 & 8 & $(7.5,7.9,8.1,8.5)$ & $(7.5,7.9,8.1,8.5)$ & & 0.30 & 3586170.1 \\
7 & 10 & $(7.5,7.9,8.1,8.5)$ & $(7.5,7.9,8.1,8.5)$ & & 1.3 & 9082798.9 \\
8 & 4 & $(9.5,9.9,10.1,10.5)$ & $(7.5,7.9,8.1,8.5)$ & & 0.84 & 7346019.5 \\
9 & 6 & $(9.5,9.9,10.1,10.5)$ & $(7.5,7.9,8.1,8.5)$ & & 0.38 & 4279488.0 \\
10 & 8 & $(9.5,9.9,10.1,10.5)$ & $(7.5,7.9,8.1,8.5)$ & & 1.2 & 8999197.4 \\
11 & 4 & $(11.5,11.9,12.1,12.5)$ & $(7.5,7.9,8.1,8.5)$ & & 0.98 & 8755211.8 \\
12 & 6 & $(11.5,11.9,12.1,12.5)$ & $(7.5,7.9,8.1,8.5)$ & & 1.1 & 8992186.5 \\
\hline
\end{tabular}

determining factor. Thus, it can be concluded that an optimal solution exists when the summation of initial inventory, domestic supply, and imports minus demand is less than the capacity of long-term storage facilities.

$$
\begin{aligned}
\text { Initial inventory } & + \text { domestic supply }+ \text { import } \\
& - \text { demand } \leq \text { longterm capacity } .
\end{aligned}
$$

Note that as domestic supply and demand are fuzzy numbers and import is a decision variable that is determined after the problem is solved, Eq. (28) is approximate.

Here, we investigated the feasible region for different values of the initial inventory, supply, and demand. Four values for the initial inventory $(4,6,8$, and 10 million tonnes) were considered. Intra-layer flows between facilities are allowed and $\alpha=\beta=0.9$. The results are presented in Table 8 and support Eq. (28). Note that if a problem is feasible, it will remain feasible when demand is increased because demand withdraws from storage facilities and creates a space for storage. It also remains feasible when initial inventory or domestic supply decreases for a similar reason.

\section{Conclusion}

In this paper, an uncertain mixed-integer linear programming model was developed for integrated planning of imports, transportation, storage, and distribution of wheat in Iran. This model addressed supplier selection, order planning, transportation, storage, and distribution of imported and domestically supplied wheat while considering wheat's quality and sleep period. This paper is one of the very few studies that differentiated between storage facilities in the field of grain supply chain management and to the best of our knowledge, it is the first one that considers intralayer flows between storage facilities. Also, it takes into account the uncertainties associated with wheat prices, domestic supply, and demand. Since we face a lack of sufficient and reliable historical data, the Fuzzy Chance-constrained Programming approach was used to handle the uncertain parameters. Applicability and advantages of the developed model were demonstrated using real data from the wheat supply chain of Iran. Results demonstrated that optimization of decisions would lead to a significant reduction in total costs; hence, developing an online information system and software based on the proposed model is strongly recommended for making optimal decisions.

According to the reports published annually by "Iran Road Maintenance \& Transportation Organization", wheat is the 2nd most transported goods in Iran. It occupies most of the transportation capacity and creates much road traffic. However, as it was shown in this paper, transportation plans are far from optimality. Optimization of transportation plans can quickly reduce transportations by about $26 \%$ on average (Table 5). Also, in Iran, unlike the world's primary producers and exporters of wheat, rail transportation's share is meager. The results show that although the rail transportation capacity for transporting bulk grain is a limiting factor, the current capacity is not used correctly and rail transportation is not optimal.

Finally, as was shown in Section 6, using short- 
term storage facilities can reduce transportation costs. At present, these facilities are only used when the capacity of long-term storage facilities is fully utilized. However, appropriate usage of short-term storage facilities can lead to cost reduction. As the domestic supply of wheat increases, the role of short-term storage facilities in cost reduction becomes more significant. Therefore, considering the fact that domestic supply is about 11.5 million tonnes at present, the appropriate usage of short-term storage facilities has become more critical.

For future research, considering a multi-product supply chain is suggested, where different qualities are needed for different purposes. Second, assessing the need for building new long-term storage facilities and opening temporary short-term storage facilities is recommended too. Since, at present, storage capacity in some provinces is not proportional to their production and consumption quantity, redesigning the wheat supply chain network can have remarkable impacts on total transportation costs. Third, applying other non-deterministic programming approaches, especially robust programming approaches, is recommended for future studies. Finally, considering the possibility of exporting surplus wheat to neighbors is suggested for future research.

\section{Acknowledgment}

This paper presents some results of a research project concerning the wheat supply chain of Iran that was funded by "Iran Road Maintenance \& Transportation Organization." The authors of this paper would like to express their special thanks and gratitude to the following people and organizations for their assistance and support in the data collection process and for reviewing and confirming the results: Dr. Adamnejad, Eng. Teimouri, Mr. Broujerdi, Dr. Fallahkohan, Mr. Ghanbari, Eng. Niyafar, Eng. Sharifpour, Eng. Pourazari, Eng. Dibaee, Eng. Mohri, "Iran Road Maintenance \& Transportation Organization", "Government Trading Organization of Iran", "Ministry of Agriculture-Jihad", "The Railways of Islamic Republic of Iran", and "Ports \& Maritime Organization of Iran."

\section{References}

1. Bedford, D., Claro, J., Giusti, A.M., et al., Food Out -look Biannual Report on Global Food Markets (2017).

2. Denicof, M.R., Prater, M.E., and Bahizi, P., Wheat Transportation Profile, United States Department of Agriculture (2014).

3. Ahumada, O. and Villalobos, J.R. "Application of planning models in the agri-food supply chain: A review", Eur. J. Oper. Res., 196(1), pp. 1-20 (2009).
4. Tsolakis, N.K., Keramydas, C.A., Toka, A.K., et al. "Agrifood supply chain management: A comprehensive hierarchical decision-making framework and a critical taxonomy", Biosyst. Eng., 120, pp. 47-64 (2014).

5. Handayati, Y., Simatupang, T.M., and Perdana, T. "Agri-food supply chain coordination: the state-of-theart and recent developments", Logist. Res., 8(1), p. 5 (2015).

6. Kusumastuti, R.D., Van Donk, D.P., and Teunter, R. "Crop-related harvesting and processing planning: A review", Int. J. Prod. Econ., 174, pp. 76-92 (2016).

7. Sheikhi, A. and Nazeman, H. "Developing a model for scheduling and distribution planning of Iran's wheat imports", Iran. J. Trade Stud. Q., 29(8), pp. 73-102 (2004).

8. Bilgen, B. and Ozkarahan, I. "A mixed-integer linear programming model for bulk grain blending and shipping", Int. J. Prod. Econ., 107(2), pp. 555-571 (2007).

9. O'Donnell, B., Goodchild, A., Cooper, J., et al. "The relative contribution of transportation to supply chain greenhouse gas emissions: A case study of American wheat", Transp. Res. Part Transp. Environ., 14(7), pp. 487-492 (2009).

10. Thakur, M., Wang, L., and Hurburgh, C.R. "A multiobjective optimization approach to balancing cost and traceability in bulk grain handling", J. Food Eng., 101(2), pp. 193-200 (2010).

11. Asgari, N., Farahani, R.Z., Rashidi-Bajgan, H., et al. "Developing model-based software to optimise wheat storage and transportation: A real-world application", Appl. Soft Comput., 13(2), pp. 1074-1084 (2013).

12. Casals, L.C. and García, B.A. "Wheat interchanges in Europe: Transport optimization reduces emissions", Transp. Res. Part Transp. Environ., 41, pp. 416-422 (2015).

13. An, K. and Ouyang, Y. "Robust grain supply chain design considering post-harvest loss and harvest timing equilibrium", Transp. Res. Part E Logist. Transp. Rev., 88, pp. 110-128 (2016).

14. Hyland, M.F., Mahmassani, H.S., and Mjahed, L.B. "Analytical models of rail transportation service in the grain supply chain: Deconstructing the operational and economic advantages of shuttle train service", Transp. Res. Part E Logist. Transp. Rev., 93, pp. 294315 (2016).

15. Mahmoudinia, M., Soleimani Sedehi, M., and Karimi, B. "Wheat supply chain network design using a hublocation approach and considering rail and road transportation modes", Q. J. Transp. Eng., 8(1), pp. 125140 (2016).

16. Nourbakhsh, S.M., Bai, Y., Maia, G.D., et al. "Grain supply chain network design and logistics planning for reducing post-harvest loss", Biosyst. Eng., 151, pp. 105-115 (2016). 
17. Gholamian, M.R. and Taghanzadeh, A.H. "Integrated network design of wheat supply chain: A real case of Iran", Comput. Electron. Agric., 140, pp. 139-147 (2017).

18. Mogale, D.G., Kumar, S.K., Márquez, F.P.G., et al. "Bulk wheat transportation and storage problem of public distribution system", Comput. Ind. Eng., 104, pp. 80-97 (2017).

19. Teimoury, E., Pourmohammadi, F., and Seyyed Jifroudi, S.A. "An integrated location-allocation model for redesigning Iran's wheat supply chain network: a robust optimization approach", In The First International Conference on Systems Optimization and Business Management, Babol, Iran (2017).

20. Essien, E., Dzisi, K.A., and Addo, A. "Decision support system for designing sustainable multistakeholder networks of grain storage facilities in developing countries", Comput. Electron. Agric., 147, pp. 126-130 (2018).

21. Hajikhani, A., Khalilzadeh, M., and Sadjadi, S.J. "A fuzzy multi-objective multi-product supplier selection and order allocation problem in supply chain under coverage and price considerations: An urban agricultural case study", Sci. Iran., 25(1), pp. 431-449 (2018).

22. Mogale, D.G., Kumar, M., Kumar, S.K., et al. "Grain silo location-allocation problem with dwell time for optimization of food grain supply chain network", Transp. Res. Part E Logist. Transp. Rev., 111, pp. 40-69 (2018).

23. Maiyar, L.M. and Thakkar, J.J. "Modelling and analysis of intermodal food grain transportation under hub disruption towards sustainability", Int. J. Prod. Econ., International Journal of Production Economics, 217, pp. 281-297 (2019).

24. Mula, J., Poler, R., and Garcia, J.P. "MRP with flexible constraints: A fuzzy mathematical programming approach", Fuzzy Sets Syst., 157(1), pp. 74-97 (2006).

25. Azadeh, A., Kokabi, R., and Hallaj, D. "Credibilitybased fuzzy mathematical programming for biobjective capacitated partial facility interdiction with fortification and demand outsourcing model", Sci. Iran. Trans. E Ind. Eng., 24(2), p. 778 (2017).

26. Liu, B. and Iwamura, K. "Chance constrained programming with fuzzy parameters", Fuzzy Sets Syst., 94(2), pp. 227-237 (1998).

27. Pishvaee, M.S., Razmi, J., and Torabi, S.A. "Robust possibilistic programming for socially responsible supply chain network design: A new approach", Fuzzy Sets Syst., 206, pp. 1-20 (2012).

28. Hajiagha, R., Hossein, S., Hashemi, S.S., et al. "Hybrid fuzzy-stochastic approach for multi-product, multi-period, and multi-resource master production scheduling problem: case of a polyethylene pipe and fitting manufacturer", Sci. Iran., 26(3), pp. 1809-1823 (2019).

29. Dubois, D. and Prade, H. "The mean value of a fuzzy number", Fuzzy Sets Syst., 24(3), pp. 279-300 (1987).

30. Heilpern, S. "The expected value of a fuzzy number", Fuzzy Sets Syst., 47(1), pp. 81-86 (1992).

31. Zadeh, L.A. "Fuzzy sets as a basis for a theory of possibility", Fuzzy Sets Syst., 1(1), pp. 3-28 (1978).

\section{Appendix}

Assume that $\tilde{\xi}$ is a fuzzy number with the following membership function:

$$
\mu_{\tilde{\xi}}(x)=\left\{\begin{array}{lll}
f_{\widetilde{\xi}}(x) & \text { if } \quad \xi^{(1)} \leq x<\xi^{(2)} \\
1 & \text { if } \quad \xi^{(2)} \leq x \leq \xi^{(3)} \\
g_{\widetilde{\xi}}(x) & \text { if } \quad \xi^{(3)}<x \leq \xi^{(4)} \\
0 & \text { if } \quad x<\xi^{(1)}, \quad x>\xi^{(4)}
\end{array}\right.
$$

Then, the upper $\left(E^{*}\right)$ and lower $\left(E_{*}\right)$ expected values of $\widetilde{\xi}$ can be defined using the Choquet integral as follows [29]:

$$
\begin{aligned}
& E^{*}(\widetilde{\xi})=\xi^{(3)}+\int_{\xi^{(3)}}^{\xi^{(4)}} g_{\widetilde{\xi}}(x) d x, \\
& E_{*}(\widetilde{\xi})=\xi^{(2)}-\int_{\xi^{(1)}}^{\xi^{(2)}} f_{\widetilde{\xi}}(x) d x .
\end{aligned}
$$

According to Eqs. (A.2) and (A.3), the Expected Value $(E V)$ of $\widetilde{\xi}$ can be defined as follows [30]:

$$
E V[\widetilde{\xi}]=\frac{E^{*}(\widetilde{\xi})+E_{*}(\widetilde{\xi})}{2} .
$$

If $\widetilde{\xi}$ has a trapezoidal possibility function (Figure 3 ), then we have:

$$
E V[\widetilde{\xi}]=\frac{\xi^{(1)}+\xi^{(2)}+\xi^{(3)}+\xi^{(4)}}{4} .
$$

Now, let $r$ be a real number. The possibility (Pos) of $\widetilde{\xi} \leq r$ is defined as follows [31]:

$$
\operatorname{Pos}\{\widetilde{\xi} \leq r\}=\sup _{x \leq r} \mu_{\widetilde{\xi}}(x)
$$

If $\widetilde{\xi}$ has a trapezoidal possibility function, the possibility of $\widetilde{\xi} \leq r$ can be written as follows: 


$$
\operatorname{Pos}\{\tilde{\xi} \leq r\}= \begin{cases}1, & \xi^{(2)} \leq r \\ \frac{r-\xi^{(1)}}{\xi^{(2)}-\xi^{(1)}}, & \xi^{(1)} \leq r \leq \xi^{(2)} \\ 0, & r \leq \xi^{(1)}\end{cases}
$$

Thus, it can be concluded that:

$$
\operatorname{Pos}\{\widetilde{\xi} \leq r\} \geq \alpha \Leftrightarrow r \geq(1-\alpha) \cdot \xi^{(1)}+\alpha \cdot \xi^{(2)} .
$$

\section{Biographies}

Fahimeh Pourmohammadi is a $\mathrm{PhD}$ candidate at Iran University of Science and Technology (IUST), Tehran, Iran. Her research interests include agri-food supply chain management, poultry supply chain management, and reverse logistics.

Ebrahim Teimoury is an Associate Professor at the School of Industrial Engineering at Iran University of Science and Technology (IUST), Tehran, Iran. He received his $\mathrm{PhD}$ from Iran University of Science and Technology in 2000 and initiated his work as a faculty member in 2001. He has published and presented more than 150 papers in many national and international journals and conferences. His research is mainly concentrated on supply chain management and systems thinking and approaches.

Mohammad Reza Gholamian is an Associate Professor in the School of Industrial Engineering at Iran University of Science and Technology (IUST), Tehran, Iran. Presently, he is a faculty member of Logistics and Supply Chain Management and is actively engaged in conducting academic, research, and development programs in the field of industrial engineering. He has contributed more than 180 research papers to many national and international journals and conferences. His research interests include inventory models, supply chain network design, and multi-criteria decision-making. 